\title{
Generalization of activity following discriminative punishment training*
}

\author{
JOHN B. CARMAN \\ University of North Dakota, Grand Forks, N. Dak. 58201
}

The effect of discriminative punishment upon gross activity of the rat was investigated. When activity level was measured concurrent with the punished lever response, reliable decrement of both responses was observed. Generalization gradients, obtained in absence of the opportunity to emit the punished response, suggest that the suppression and modification of activity produced by the discriminative punishment procedure could determine the course of change in frequency and pattern of discrete reinforced operants.

Recently, Stein, Hoffman, \& Stitt (1971) assessed the changes in collateral behaviors generated by the Estes-Skinner (1941) conditioned suppression procedure and reported, for pigeons, that the preshock stimulus reduced all overt activity and caused the pigeon to "freeze." This finding agrees with the observations of other investigators who have attributed the Estes-Skinner effect to decrements in the level of skeletal behaviors which support the reinforced referent operant (Hunt \& Brady, 1955; Hoffman \& Barrett, 1971). The present report describes the generalization of suppressed gross activity following discriminative p un is hment training-a response-contingent aversive stimulus procedure (cf. Azrin, 1956) which generates the contingency for the development of conditioned suppression (Church, Wooten, \& Matthews, 1971). The data reported here were taken from a more extensive investigation of the changes in collateral behaviors following discriminative punishment training (Carman, 1971).

\section{METHOD}

The Ss were three male Sprague-Dawley albino rats, matched for weight and numbered R1, R2, and R3. They were maintained at $85 \%$ free-feeding body weight and were approximately 150 days old. The Ss had had previous experience with various ratio schedules of food reinforcement.

A Scientific Prototype A-102 box containing a retractable lever served as the experimental chamber. The standard floor was replaced with a bronze rod grid floor which was suspended by expansion springs from the outer corners. A variable inductance transducer which was sensitive to both vertical and lateral grid displacements was loaded to the

* This study was supported by Contract No. NOOO14-68-A-0499 (NR 101-753) between the Office of Naval Research, Dept. of the Navy, and the University of North Dakota and by PHS Grant MH 17745-01. grid frame. The amplified transducer output keyed a relay for digital recording of grid displacement frequency. The amplifier was adjusted to record activity from a lower threshold of "just noticeable" skeletal position shifts. The lever microswitch required $12 \mathrm{~g}$ to actuate. A white noise background of $40 \mathrm{~dB}$ and a $6 \cdot \mathrm{W}$ houselight were continuously present inside the chamber. Tone stimuli were produced by a Hewlett-Packard 201C oscillator. All sound intensities were measured at the lever with a Bruel and Kjaer 2203 meter and are referenced to $0 \mathrm{~dB}\left(.0002\right.$ dynes $\left./ \mathrm{cm}^{2}\right)$. Scrambled shock generated by a Grason-Stadler constant current source of $0.80 \mathrm{~mA}$ at $0.50 \mathrm{sec}$ duration served as the aversive stimulus. Reinforcers were $45 \cdot \mathrm{mg}$ Noyes rat pellets. Electromechanical program and recording equipment was contained in an adjacent room.

All Ss initially received eight sessions of leverpress training on a variable interval 1-min (VI 1 -min) reinforcement schedule. These and all other sessions lasted $1 \frac{1}{2} \mathrm{~h}$ and were conducted daily.

\section{Sessions 1 to 5 :}

Habituation

During each of these sessions, Ss were exposed once to tones of 500 , $1,000,1,500,2,000$, and $2,500 \mathrm{~Hz}$ at 70-dB intensity. The tone duration was $3 \mathrm{~min}$, the intertone interval was $15 \mathrm{~min}$, and the order of tone presentation was random for $S s$ and sessions. While the $S s$ were leverpressing on the VI 1-min schedule, leverpress and activity responses were recorded during each tone presentation and during the 3-min period immediately preceding the tone. These recordings were used to compute a suppression ratio (Annau \& Kamin, 1961) between the pretone and tone periods for leverpress and activity measures. The suppression ratio equals the number of responses during the tone divided by the sum of responses in the pretone and tone periods. Suppression of a response during a tone is indicated if the ratio is less than 0.50 . Ratio values greater than 0.50 indicate an increase in frequency of that response during a tone. The suppression ratio expresses the relative difference in rate between pretone and tone periods for each response measure.

Sessions 5 to 9 :

Activity Training

During these sessions, the lever was retracted from the chamber and reinforcers were delivered as primed by the VI $1-\mathrm{min}$ schedule. The $3-\mathrm{min}$ tones were presented in random order to each $\mathrm{S}$ for each session, and activity responses were used to compute activity suppression ratios.

Sessions 9 to 13 :

Leverpress Training

Leverpressing was reinforced by the VI 1-min schedule. No tones were presented to Ss.

Sessions 13 to 23 :

Discriminative Punishment Training

Ten sessions of discriminative punishment training were given while Ss were leverpressing on the VI 1-min schedule. For each session, four presentations of the $3-\min 1,500-\mathrm{Hz}$ tone occurred at regular $15-\mathrm{min}$ intervals. During the tone, shock was primed on a random interval schedule. Shocks in each 1 -min segment of the tone were programmed independently and the probability of shock was 0.05 per 3-sec interval. Shocks primed but not delivered during any 1 -min interval or any trial were canceled. Leverpress and activity responses were recorded and suppression ratios were computed for each measure.

Sessions 23 to 31 :

Activity Generalization Testing

Treatment and response measures during these sessions were identical to those of Sessions 5 to 9.

\section{RESULTS AND DISCUSSION}

The discriminative punishment procedure resulted in substantial decreases in the frequency of preshock tone responding for both leverpress and activity. Table 1 provides the suppression ratios by two session blocks during habituation and discriminative punishment training. Sandler's A statistic (cf. Runyon \& Haber, 1971, p. 210) was used for a one-tailed assessment of the decline in group mean suppression ratios for both response measures between Sessions 1-4 and 19-22. As suggested in Table 1 , the leverpress and activity ratios were reliably depressed $(A=$ .333 , df $=2, p<.0005 ; A=.387, d f=$ $2, \mathrm{p}<.05$, respectively).

Figure 1 depicts the suppression ratios in two session blocks during all tones for habituation (Sessions 1-4) and generalization testing (Sessions 23-30). In general, activity was uniformly suppressed during Sessions 23-24 across all tone values. S R1 showed peak suppression to the 2,000-Hz tone, while $\mathrm{R3}$ exhibited 
Table 1

Suppression Ratios for Habituation and Discriminative Punishment Training to $1500-\mathrm{Hz}_{2}$ Tone

\begin{tabular}{|c|c|c|c|c|c|c|}
\hline \multirow[b]{2}{*}{$\begin{array}{l}\text { Treatment } \\
\text { (Sessions) }\end{array}$} & \multicolumn{2}{|c|}{ S R1 } & \multicolumn{2}{|c|}{ S R 2} & \multicolumn{2}{|c|}{ S R3 } \\
\hline & $\begin{array}{l}\text { Lever } \\
\text { Press }\end{array}$ & Activity & $\begin{array}{l}\text { Lever } \\
\text { Press }\end{array}$ & Activity & $\begin{array}{l}\text { Lever } \\
\text { Press }\end{array}$ & Activity \\
\hline \multicolumn{7}{|l|}{ Habituation } \\
\hline $\begin{array}{l}1 \cdot 4 \\
\text { Punishment }\end{array}$ & .50 & .51 & .48 & .51 & .51 & .49 \\
\hline $13-14$ & .05 & .30 & .21 & .30 & .23 & .46 \\
\hline $15 \cdot 16$ & .02 & .29 & .01 & .25 & .04 & .42 \\
\hline $17-18$ & .02 & .35 & .01 & .33 & .01 & .37 \\
\hline $19 \cdot 20$ & .01 & .18 & .00 & .29 & .02 & .35 \\
\hline $21 \cdot 22$ & .02 & .24 & .00 & .32 & .05 & .43 \\
\hline
\end{tabular}

maximum suppression to $1,000 \mathrm{~Hz}$. S R2 showed substantial and uniform suppression to the $500-, 1,000-$, and $1,500-\mathrm{Hz}$ tones and only slight suppression to the 2,000- and $2,500-\mathrm{Hz}$ tones, During Sessions 25-26, activity suppression was maximum at $1,500 \mathrm{~Hz}$ for all Ss. For $R 2$ and $R 3$, the peak suppression of activity to the $1,500-\mathrm{Hz}$ tone during Sessions 25-26 was greater than the suppression to any tone value during Sessions 23-24. Activity suppression declined for all Ss from Session 27 through Session 30 and closely approximated the flat unsuppressed gradients obtained during habituation.

In agreement with the findings of investigators using the Estes-Skinner procedure (Stein et al, 1971; Hunt \& Brady, 1955), discriminative punishment effectively reduced the level of gross activity during punishment sessions. The acquisition of activity suppression paralleled the course of suppression of the leverpress response, although the decrement in activity level was considerably less (Table 1). The extinction of activity suppression was orderly, but did not consistently follow the function which describes the extinction of specific operants suppressed by the Estes-Skinner procedure (Fig. 1) (cf. Hoffman, 1969). The present data extend the positive correlation between concurrent suppression of the reinforced operant and gross activity reported by Stein et al (1971) in that the suppression of activity was observed in absence of the opportunity to emit the previously punished response. This finding strongly suggests the more primary and determining role of activity in the suppression of discrete reinforced operants.

of particular interest is the striking similarity between the activity generalization gradients presented hero and the conditioned suppression keypeck gradients produced by the Estes-Skinner procedure reported by Hoffman \& Fleshler (1961). These investigators found that initial generalization tests produced gradients combination with (2) the ogive extinction function of the conditioned suppression effect for all test stimuli. The group curves of Fig. 1 cannot be so derived. Such an analysis will account for the sharpening trend exhibited by the $500-, 1,000-$, and $2,500-\mathrm{Hz}$ tones during successive test blocks, but suppression to the 1,500 and $2,000-\mathrm{Hz}$ tones shows inversions in the extinction function between Sessions 23-24 and 25-26 for R2 and R3. Only the extinction function for R1 accords with the expectation generated by Hoffman's (1969) analysis. Of course, the present data differ from those treated by Hoffman in terms of general procedure, topography of the referent behavior and its relation to the maintenance reinforcement contingency, and $S$ species differences. The present results, however, may limit the generality of the theoretical extinction function for suppression in general and, consequently, the applicability of the Hoffman analysis to certain suppression generalization gradients.

An alternative, but speculative, view, which is in better agreement
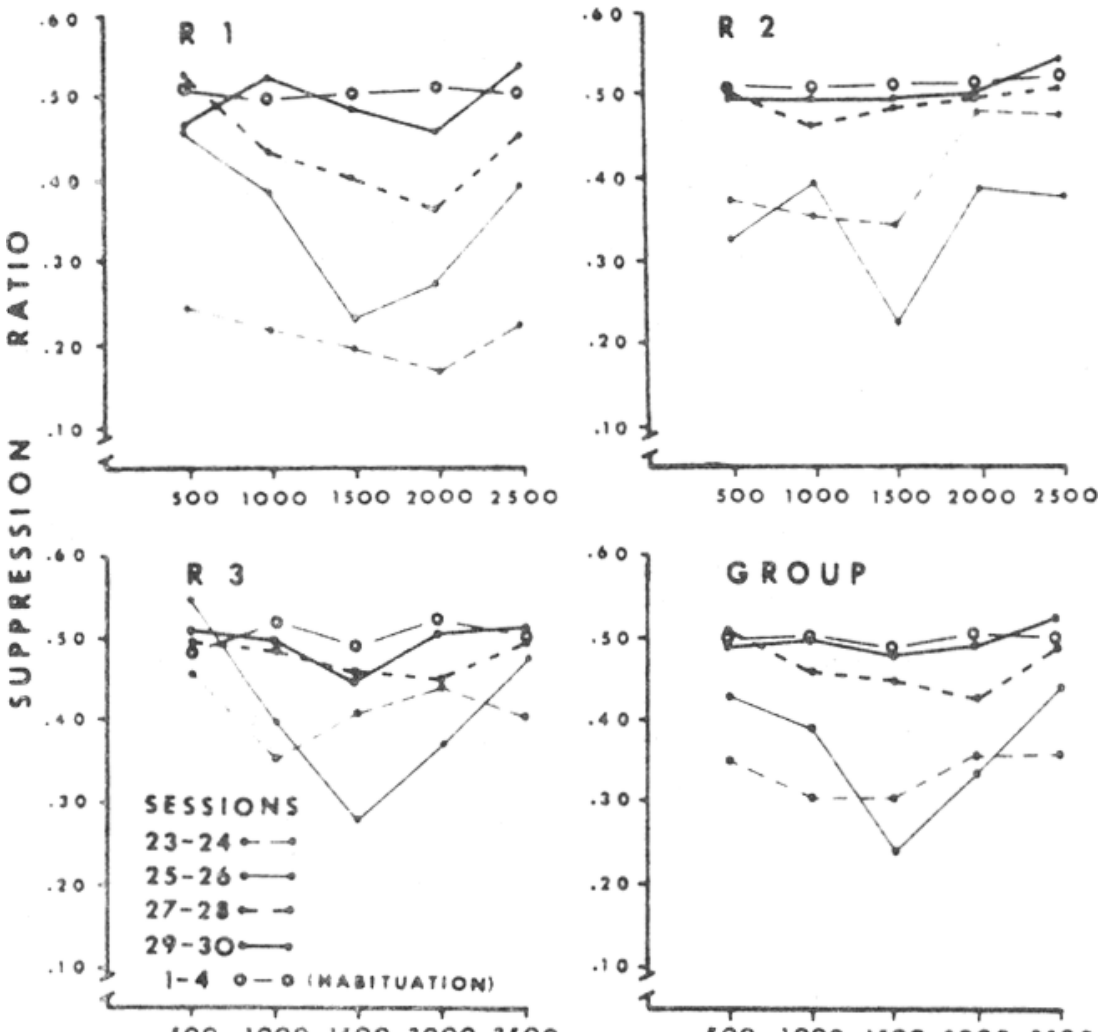

$300 \quad 1000 \quad 1300 \quad 2000 \quad 3500$

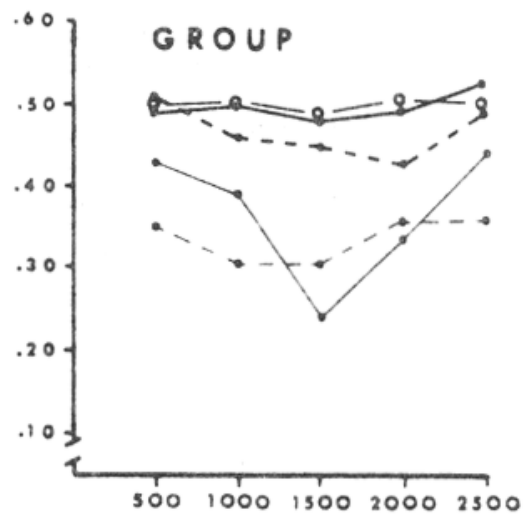

TONE FREQUENCY $\left(\mathrm{Hz}_{\mathrm{z}}\right)$

Fig. 1. Generalization gradients for activity suppression ratios for habituation and extinction. 
with both the individual and group data of Fig. 1, suggests that some cue more salient than tone frequency, possibly tone onset or tone perse, may have acquired suppressive properties during discriminative punishment training and was responsible for the initial nonfrequency-specific suppression of Sessions 23-24. If suppression to such a cue extinguished during Sessions 23-24, then suppression controlled by the less dominant frequency dimension cue could be exhibited during Sessions 25-26. Such an analysis suggests the paradoxical case of maximum suppression under control of a subordinate cue. However, the discriminative punishment acquisition data support such an interpretation. The number of shocks received in acquisition were 10,15 , and 22 for R1, R2, and R3, respectively. If the salience of a cue such as tone onset decreases with the number of punished trials to the $1.500-\mathrm{Hz}$ tone, then during initial generalization testing $R 1$ would be expected to exhibit maximum suppression across all tones with R2 and R3 displaying, respectively. less.
The individual data of Fig. 1 indicates such an ordering of suppression does exist across the Ss. In addition, the generalization gradients for all Ss across Sessions $25-26$ appear to be somewhat less stable than those of Sessions 23-24 and 27-28, which suggests the possibility of a transition in the control of suppression between these test sessions. Although such a post hoc analysis of the sharpening of the obtained activity suppression generalization gradients is suggestive for future work, the present results do indicate that behaviors such as gross activity undergo changes which may determine the course of change for specific reinforced operants.

REFERENCES
ANNAU. Z.. \& KAMIN. L. J. The
conditioned emotional response as a
function of the intensity of the US.
Journal of Comparative \& Physiological
Psychology. $1961,54.428-432$.
AZRIN. N. Some ef fects of two
intermittent schedules of immediate and
nonimmediate punishment. Journal of
Psychology, 1956. 42 . $3-21$.
CARMAN, J. B. Discriminated punishment
and collateral behavior. Paper presented
at the annual meeting of the
Psychonomic Society. St. Louis. 1971 .

CHURCH, R. H., WOOTEN, C. L.. \& MATTHEWS. T. J. Contingency between a response and an aversive event in the rat. Journal of Comparative \& Physiological Psychology. 1970, 72. 476.485 .

ESTES, W. K \& SKINNER, B. F. Some quantitative properties of anxiety. Journal of Experimental Psychology $1941,29,390-400$.

HOFFMAN, H. S. Stimulus generalization versus discrimination failure in conditioned suppression. In R. M. Gilbert and N. S. Sutherland (Eds.), Animal discrimination learning. New York: Academic Press, 1969

HOFFMAN. H. S., \& BARRETT, J. Overt activity during conditioned suppression: A search for punishment artifacts. Journal of the Experimental Analysis of Behavior, 1971, 16, 343-348.

HOFFMAN, H. S., \& FLESHLER. M. Stimulus factors in aversive control: The generalization of conditioned suppression. Joumal of the Experimental Analysis of Behavior, 1961, 4, 371-378.

HUNT. H. F.. \& BRADY, J. V. Some effects of punishment and intercurrent anxiety on a simple operant. Journal of Comparative \& Physiological Psychology. 1955. 48, 305-310.

RUNYON, R. P., \& HABER, A Fundamentals of behavioral statistics. London: Addison-Wesley, 1971.

STEIN, N., HOFFMAN, H. S, \& STITT, C. Collateral behavior of the pigeon during conditioned suppression of key pecking. Journal of the Experimental Analysis of Behavior, 1971, 15, 83-93. 